\title{
Leukopenia and hepatic failure in a case of yellow phosphorus poisoning
}

\author{
Syed Mohammad Wamiq ${ }^{1}$, Neha Singh¹, Abhinav Tiwari', Sambita Panda ${ }^{2}$, G Malini Chandramohan ${ }^{3}$ \\ From ${ }^{1}$ DNB Resident, ${ }^{2}$ Senior Deputy Director, ${ }^{3}$ Director, Department of Pediatrics, Jawaharlal Nehru Hospital and Research Center, Bhilai, \\ Chhattisgarh, India
}

\begin{abstract}
Rat poison is easily available in India. When ingested the yellow phosphorus content of this poison generally leads to hepatic failure and death, unless a liver transplant is offered. We present here a case of yellow phosphorus ingestion who developed hepatic failure and severe leukopenia. The patient was managed conservatively and recovered within 3 weeks of intensive treatment.
\end{abstract}

Key words: Hepatic failure, Rat poison, Yellow phosphorus

$\mathrm{R}$ at poison (Ratol), containing 3\% yellow phosphorus, is nowadays, commonly available which can be rapidly fatal. Elemental phosphorus exists in two forms - red and yellow. Red phosphorus is non-volatile, insoluble, and unabsorbed, and therefore, non-toxic when ingested. On the other hand, yellow phosphorus (referred to as white phosphorus) is a severe local and systemic toxin causing damage to gastrointestinal, hepatic, cardiovascular, and renal systems. White phosphorus is used as a rodenticide and in fireworks. The rodenticide is available as powder or pastes containing $2-5 \%$ of yellow phosphorus [1].

\section{CASE REPORT}

A 16-year-old girl was referred to the pediatrics department of our hospital with an alleged history of ingestion of rodenticide paste (Ratol, containing 3\% yellow phosphorus) (Fig. 1) of an unknown quantity. The girl had taken it after a family quarrel as a deliberate attempt to suicide. The family members came to know about it, $14 \mathrm{~h}$ after ingestion. She was first brought to a local hospital and was finally referred to our hospital after $18 \mathrm{~h}$ of ingestion with complaints of pain in the abdomen and persistent vomiting. There was no history of lethargy, altered sensorium, convulsions, jaundice, breathlessness, or oliguria, Melena, or bleeding.

She was conscious and oriented to time, place, and person. She was afebrile with pulse and blood pressure being normal. No pallor, icterus, cyanosis, clubbing, or edema were noted. There was no garlic odor. No bleeding manifestations were present. Scar marks were seen on the extensor aspect of the left forearm. No hepatomegaly or splenomegaly was seen. The liver span was

\section{Access this article online}

Received - 04 September 2020

Initial Review - 11 September 2020

Accepted - 09 October 2020

DOI: $10.32677 / \mathrm{IJCH} .2020 . v 07.110 .007$
$8 \mathrm{~cm}$. No abdominal tenderness, no guarding, or rigidity were noted. No bruises or petechiae were seen. Other systems were essentially normal.

The child was admitted and gastric lavage was done and investigations were sent. Results of investigations done on the day of admission and subsequently are summarized in Table 1 . On day 2 of admission, the patient had a fall in blood pressure, icterus was seen, and was noticed that the patient was dull. Based on the clinical signs and symptoms and laboratory parameters, she was diagnosed as a case of acute liver failure. She was started on intravenous (IV) fluids, IV antibiotics, Vitamin K, proton-pump inhibitors, antiemetics, oral lactulose, and tablet ursodeoxycholic acid. Input-output was strictly monitored. Ultrasound abdomen was done. Blood sugar monitoring was done regularly. Daily prothrombin time, activated partial thromboplastin time, and international normalized ratio were evaluated.

Due to multiple episodes of Melena and bleeding per rectum, fresh frozen plasma (FFP) was repeatedly infused. $\mathrm{N}$-Acetylcysteine (NAC) was administered according to standard clinical practice guidelines [2].

The patient deteriorated over the next $48 \mathrm{~h}$. She developed deep icterus, had low hemoglobin count in due course of hospital stay, very low total leukocyte count, and platelet count, because of pancytopenia. The differential diagnosis of pancytopenia was ruled out, such as infection, megaloblastic anemia, malignant infiltration, aplastic anemia, storage disorders, immune disorders through history and investigations, and a bone marrow biopsy was done. The impression of bone marrow was cellular showing mild normoblastic erythroid hyperplasia, no abnormal cell deposit, or granuloma was seen. The granulocyte colony-stimulating factor was given due to very low leukocyte count.

Correspondence to: Neha Singh, Department of Pediatrics Jawaharlal Nehru Hospital and Research Centre, Bhilai, Chhattisgarh, India. E-mail: nehasingh2688@gmail.com

(C) 2020 Creative Commons Attribution-NonCommercial 4.0 International License (CC BY-NC-ND 4.0). 
After a plateau of 2 days, the patient started improving, as sensorium improved, appetite increased, Melena stopped, and simultaneous improvement of laboratory parameters seen. A psychiatry consultation and counseling were done. The patient had a good recovery and was discharged on day 11 with the advice of follow-up after 2 weeks. On follow-up, the patient had recovered completely and her laboratory parameters were also normal (Table 1).

\section{DISCUSSION}

Studies had shown that yellow phosphorus is the most common rodenticide used in suicidal attempts with $30 \%$ mortality, despite maximal supportive therapy [2]. Yellow phosphorous is rapidly absorbed in the intestinal tract and a few hours after ingestion $69-73 \%$ of the total ingested dose concentrates into the liver where severe complication develops with smaller concentration reaching the brain, striated muscles, and kidneys.

The lethal dose in yellow phosphorus poisoning is $10 \mathrm{mg} / \mathrm{kg}$ body weight; however, the ingestion of $100 \mathrm{mg}$ of dose may also result in death. Indicators for poor outcomes include early elevation of liver transaminases and alkaline phosphatases, more than 10-fold increase in alanine aminotransferase, derangements in prothrombin time (as in our case), metabolic acidosis, and hypoglycemia [2].

The mechanism of toxicity of yellow phosphorous is using an exothermic reaction producing phosphoric acid that causes direct tissue damage due to the production of free radicals against

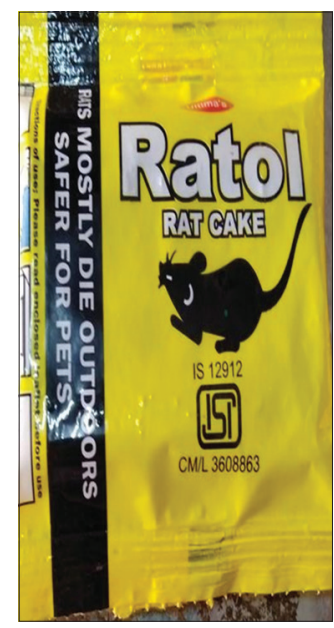

Figure 1: Image of Ratol poison

Table 1: Laboratory investigations

\begin{tabular}{|c|c|c|c|c|c|c|c|c|c|c|c|c|}
\hline $\begin{array}{l}\text { Laboratory } \\
\text { investigations }\end{array}$ & Day 1 & Day 2 & Day 3 & Day 4 & Day 5 & Day 6 & Day 7 & Day 8 & Day 9 & Day 10 & Day 11 & $\begin{array}{c}2 \text { weeks after } \\
\text { discharge }\end{array}$ \\
\hline $\mathrm{Hb}(\mathrm{gm} / \mathrm{dL})$ & 12.9 & & 10.9 & 10.7 & 10.4 & & 10.2 & 9.3 & & & & 9.8 \\
\hline PCV (\%) & 39.3 & & & 33.8 & 33.4 & & & 29 & & & & 30.8 \\
\hline $\begin{array}{l}\text { TLC } \\
\text { (cells } / \mu \mathrm{l})\end{array}$ & 4100 & & 2200 & 1900 & 2200 & & 8400 & 20,700 & & & & 50,000 \\
\hline \multicolumn{13}{|l|}{ DLC } \\
\hline $\mathrm{N}$ & 63 & & 18 & 40 & 8 & & 29 & 78 & & & & 47 \\
\hline $\mathrm{L}$ & 34 & & 66 & 46 & 70 & & 70 & 20 & & & & 40 \\
\hline $\mathrm{E}$ & 2 & & 2 & 0 & 0 & & 1 & 2 & & & & 3 \\
\hline M & 2 & & 4 & 6 & 2 & & 0 & 0 & & & & 10 \\
\hline $\begin{array}{l}\text { Platelet } \\
\text { count } \\
\left(\text { cells } / \mathrm{mm}^{3}\right)\end{array}$ & 13,000 & & 80,000 & 78,000 & 80,000 & & 72,000 & 113,000 & & & & 223,000 \\
\hline $\begin{array}{l}\text { Total serum } \\
\text { bilirubin }\end{array}$ & 0.8 & & 2.3 & & 6.9 & & 8.4 & 6.6 & & & 2.9 & 1.3 \\
\hline AST & 47 & & 341 & & 834 & & 374 & 431 & & & 184 & 37 \\
\hline ALT & 13 & & 69 & & 278 & & 146 & 177 & & & 126 & 19 \\
\hline ALP & 120 & & 169 & & 250 & & 306 & & & & 273 & 88 \\
\hline Serum urea & 19 & & 56 & & 40 & & & & & & 16 & \\
\hline $\begin{array}{l}\text { Serum } \\
\text { creatinine }\end{array}$ & 0.9 & & 0.9 & & 1 & & & & & & 0.6 & \\
\hline Serum sodium & 140 & 134 & & & 131 & & & & & & & \\
\hline $\begin{array}{l}\text { Serum } \\
\text { potassium }\end{array}$ & 4.2 & 3.6 & & & 2.9 & & & & & & & \\
\hline PT & & 67.7 & 28 & & 32.2 & 16.6 & 12.9 & 13.1 & & & & \\
\hline aPTT & & & 31.7 & & 28.2 & & & & & & & \\
\hline INR & & 6.14 & 2.33 & & 2.71 & 1.31 & .99 & 1.01 & & & & \\
\hline
\end{tabular}

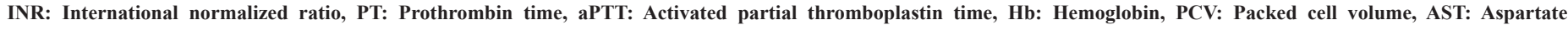

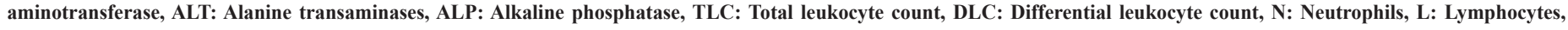
E: Eosinophils, M: Monocytes, G-CSF: Granulocyte colony-stimulating factor, IV: Intravenous 
organic molecules which leads to changes in ribosomal function and protein synthesis, failure of regulation of blood glucose, and fatty degeneration of multiple organs [2]. The clinical features of yellow phosphorus poisoning may be divided into three characteristic phases.

The first phase manifests with local effects on the gastrointestinal mucosa and lasts for $<24 \mathrm{~h}$. Children may be asymptomatic or may complain of epigastric pain, vomiting, intense thirst, and rarely, diarrhea. Stools are often dark and luminous, often referred to as smoking stool syndrome. During this stage, sudden death may occur due to the ingestion of a very large amount of yellow phosphorus, resulting from cardiovascular arrhythmia and collapse within the first $24 \mathrm{~h}$.

The second phase lasts up to 3 days (24-72 h) post-exposure and patients are characteristically asymptomatic. This may give a false impression that there is no significant toxicity and leads to premature discharge from the hospital. Children may have minor gastrointestinal symptoms, vascular collapse, and myocardial dysfunction leading to cardiogenic shock, although rare, can complicate these phases.

The third phase is characterized by the reappearance of the primary symptoms. Jaundice, often with pruritus and other features of hepatic failure, including bleeding manifestation. Temporary bone marrow suppression, isolated cholestasis, and pulmonary edema have been reported. Acute tubular necrosis leading to acute kidney injury may be seen in more than $50 \%$ of cases. Liver biopsy shows features of toxic hepatitis with extensive necrosis, ballooning degeneration, and steatosis. The cause of death includes hepatic and renal insufficiency and cardiogenic shock [1].

Elemental phosphorus induces a reduction in the cellular replication rate, arresting cells in the metaphase stage of mitosis instead of destroying them. Histopathological examination of the biopsy samples revealed unspecified bone marrow changes with normal cells and a decreased cellular mass [3].

There is no specific antidote for yellow phosphorous poisoning [4-6]. The mainstay of therapy is supportive management and measures to remove as much unabsorbed poison as possible. Gastric lavage with potassium permanganate is recommended (1:5000) to convert the phosphorous to relatively harmless oxides. Supportive therapy for hepatic failure is given.

Clinical studies in rodenticide poisoning have conflicting evidence of NAC and adjunctive therapies showed no benefit [7]. In contrast, Nalabothu et al. suggested that early use of NAC improves outcomes for all rodenticide poisonings with liver failure [8]. Similarly, in our case report, the patient recovered after giving NAC. The regimen of NAC used as a loading dose of $150 \mathrm{mg} / \mathrm{kg}$ IV over $1 \mathrm{~h}$ followed by $50 \mathrm{mg} / \mathrm{kg} \mathrm{IV}$ over $4 \mathrm{~h}$ and $100 \mathrm{mg} / \mathrm{kg}$ IV over $16 \mathrm{~h}$ [9].

In our patient, the first manifestations of intoxication were in the gastrointestinal system. On the $2^{\text {nd }}$ day of admission, she started having altered sensorium and in due course of time had Melena and acute liver failure, similar to the reports of Fernandez et al., patients with yellow phosphorus poisoning mainly present with acute hepatic failure, which was witnessed in our case [7].

The American Association for the Study of Liver Diseases guidelines for the management of acute liver failure recommends at least 1 dose of Vitamin $\mathrm{K}$ reserving FFP and platelet transfusion for those with active bleeding or needing the invasive procedure [5]. Lee et al. suggested proton-pump inhibitors or $\mathrm{H}_{2}$ receptor antagonists for ulcer prophylaxis [10]. Liver transplantation had been performed in suitable candidates for acute hepatic failure [3], as a lifesaving procedure. However, the prohibitive cost and involvement of other organs are significant limitations, and mortality remains $23 \%-73 \%$ [1].

The safest way to deal with such a lethal substance would be prevention. The indiscriminate use of yellow phosphorous in the manufacture of fireworks should be eliminated. Since most of the instances of pediatric poisoning are accidental in our country, health education regarding safe storage and disposal of these compounds can bring down the occurrence of these unfortunate accidents.

As reported in the literature, victims of yellow phosphorus poisoning may be initially symptomatic; however, recovery is observed after 2-3 days, and later on, features of acute liver failure developed, in our case, the patient had a similar progression of complication [4]. Hence, patients with acute yellow phosphorus poisoning should be monitored closely for a week since mortality is not recorded after 8 days [10]. Before discharge, her family member provided written consent to document her case without the revelation of her name.

In one case series, $87 \%$ had some hepatic derangement and $27 \%$ developed fulminant hepatic failure and died [7]. Another series found a range of $23-73 \%$ mortality depending on clinical manifestations with central nervous system manifestations portending poorer prognosis [6].

\section{CONCLUSION}

Rodenticide poisoning is common and its treatment is challenging. The onset of symptoms may be delayed and the presentation may be atypical. Even though the patient may remain asymptomatic initially, observation for a longer period is required. The treating physician should be vigilant, and excellent supportive care is one important aspect of reducing morbidity and mortality in the event of poisoning.

\section{REFERENCES}

1. Mauskar A, Mehta K, Nagotkar L, Shanbag P. Acute hepatic failure due to yellow phosphorus ingestion. Indian J Pharmacol 2011;43:355-6.

2. Kharkongor MA, Mishra AK, Ninan KF, Iyadurai R. Early use of intravenous $\mathrm{N}$-acetylcysteine in treatment of acute yellow phosphorous poisoning. Curr Med Issues 2017;15:136-8.

3. Newburger RA, Beaser SB. Phosphorus poisoning with recovery accompanied by electrocardiographic changes. Am J Med 1948;4:927-30.

4. Mohideen SK, Kumar KS. Should ratol paste be banned? Indian J Crit Care Med 2015;19:128-9.

5. Saoji AA, Lavekar AS, Salkar HR, Pawde GB, Tripathi SS. A case on suicidal poisoning associated with ratol and a perspective on yellow phosphorus poisoning. Int J Recent Trends Sci Technol 2014;10:223-5.

6. McCarron MM, Gaddis GP, Trotter AT. Acute yellow phosphorus poisoning from pesticide pastes. Clin Toxicol 1981;18:693-711.

7. Fernandez OU, Canizares LL. Acute hepatotoxicity from ingestion of yellow phosphorus-containing fireworks. J Clin Gastroenterol 1995;21:139-42. 
8. Nalabothu M, Monigari N, Acharya R. Clinical profile and outcomes of rodenticide poisoning in tertiary care hospital. Int J Sci Res Publ 2015;5:1-12.

9. Ravikanth R, Sandeep S, Philip B. Acute yellow phosphorus poisoning causing fulminant hepatic failure with parenchymal hemorrhages and contained duodenal perforation. Indian J Crit Care Med 2017;21:238-42.

10. Lee WM, Hynan LS, Rossaro L, Fontana RJ, Stravitz RT, Larson AM, et al. Intravenous $\mathrm{N}$-acetylcysteine improves transplant-free survival in early stage non-acetaminophen acute liver failure. Gastroenterology 2009;137:856-64.
Funding: None; Conflicts of Interest: None Stated.

How to cite this article: Wamiq SM, Singh N, Tiwari A, Panda S, Chandramohan GM. Leukopenia and hepatic failure in a case of yellow phosphorus poisoning. Indian J Child Health. 2020; 7(10):421-424. 